\title{
Development of History Interactive Learning Media Through Ludo Teaching to Improve Student's Critical Thinking
}

\author{
Aisyah Nur Hanifah \\ Universitas Sebelas Maret \\ aisyahhanifah0@gmail.com
}

\author{
Article History \\ accepted 1/09/2020
}

approved 4/10/2020

published 1/12/2020

\begin{abstract}
The teaching and learning process is a communication process that undergoes and changes to develop an interactive-based learning model, with the use of learning media being part of learning resources which is a combination of software (learning materials) and hardware (learning tools). Media can foster positive attitudes in students and transform the role of teachers in a more positive and productive direction. According to Reigeluth (1999), in supporting the learning process there are three learning variables, namely variables of learning conditions, methods, and variables of learning outcomes. Knowledge in historical teaching materials to Vocational Middle School Students, a teacher not only teaches theory but also through practice, like playing Ludo games. By learning to use game teaching, ludo in history learning can be a capital for teachers to act as an evaluation stage in measuring students' ability to be able to improve their thinking power through HOTS questions. The need to increase critical thinking in students, because of the enormous influence of critical thinking in improving student learning so that the results are good and following what is expected by teachers in schools. Bayer (1995), "Reasonable critical thinking." Critical thinking is useful for studying the validity of the form (statements, ideas, arguments, research, etc.).
\end{abstract}

Keywords: Interactive, game teaching, critical thinking

\begin{abstract}
Abstrak
Proses belajar mengajar pada dasarnya merupakan proses komunikasi yang mengalami perkembangan dan perubahan untuk menciptakakan model pembelajaran berbasis interaktif, dengan pemanfaatan Media pembelajaran menjadi bagian dari sumber belajar yang merupakan kombinasi antara perangkat lunak (bahan belajar) dan perangkat keras (alat belajar). Media dapat menumbuhkan sikap positif siswa dan mengubah peran guru ke arah yang lebih positif dan produktif. Menurut Reigeluth (1999), dalam menunjang proses pembelajaran ada tiga variabel pembelajaran yaitu variabel kondisi pembelajaran, metode, dan variabel hasil pembelajaran. Terutama didalam mengajarkan materi pembalajaran sejarah kepada Siswa Menengah Kejuruan, seorang guru tidak hanya mengajarkan teori namun juga melalui praktek, seperti bermain game Ludo. Dengan belajar memanfaatkan game teaching ludo dalam mempelajari sejarah, bisa menjadi modal bagi guru untuk menggunakannya sebagai tahap evaluasi dalam mengukur kemampun siswa untuk dapat meningkatkan daya berpikir kritisnya melalui soal - soal HOTS. Perlunya peningkatan berpikir kritis pada siswa, dikarenakan adanya pengaruh berpikir kritis yang sangat besar dalam meningkatkan belajar siswa agar hasilnya baik dan sesuai dengan yang diharapkan oleh guru di Sekolah. Bayer (1995), "Berpikir kritis berarti membuat penilaian-penilaian yang masuk akal". Berpikir kritis bermanfaat untuk mengevaluasi validitas berupa (pernyataan, ide-ide, argumen-argumen, penelitian, dan lain-lain).
\end{abstract}

Kata Kunci : Interaktif, game teaching, berpikir kritis

Social, Humanities, and Education Studies (SHEs): Conference Series https://jurnal.uns.ac.id/shes

p-ISSN 2620-9284 e-ISSN 2620-9292

This work is licensed under a Creative Commons Attribution-ShareAlike 4.0 International License. 


\section{SHEs: Conference Series 3 (2) (2020) 252- 266}

\section{PENDAHULUAN}

Berdasarkan UU No. 20 tahun 2003 tentang sistem pendidikan nasional menjelaskan bahwa Pendidikan adalah usaha sadar dan terencana untuk mewujudkan suasana belajar dan proses pembelajaran agar peserta didik secara aktif mengembangkan potensi dirinya sehingga dapat memiliki kekuatan spiritual, pengendalian diri, kepribadian baik, kecerdasan, akhlak mulia, serta keterampilan yang dapat diperoleh (UU.No.20,2003).

Pada impelementasi dalam keadaan realita, pendidikan akan berjalan dengan hadirnya seorang guru yang mampu mengayomi siswa agar dapat tumbuh menjadi siswa yang mandiri dan berpikir maju, yaitu melalui perencanaan pendidikan yang sebaik baiknya. (Suharsimi, 2037, hlm : 5).

Perencanaan pendidikan adalah cara guru melakukan proses pengintelektualan pada siswa untuk bisa memahami maksud dalam menganalisis, merumuskan dan menimbang serta memutuskan dengan keputusan yang diambil mampu mempunyai konsistensi (taat asasi) internal dan berhubungan secara sistematis dengan keputusankeputusan. Akan tetapi, suatu perencanaan pendidikan tidak akan berjalan maksimal tanpa peran dari seorang guru. Menurut Rohamn (2012), guru adalah sosok paling berharga dalam membawa perubahan besar pada peningkatan motivasi belajar siswa, dalam mempelajari pelajaran Sejarah, terutama siswa SMK. Permasalahan khusus yang saat ini sering sekali terjadi di dalam aktivitas pembelajaran sejarah di Sekolah Menengah Kejuruan saat ini adalah minat dan motivasi belajar siswa yang kurang. Kurangnya minat dan motivasi siswa dalam belajar tersebut, tidak hanya dilatarbelakangi karena kondisi lingkungan keluarga dan teman sebaya, namun juga minimnya motivasi belajar dari lingkungan sekolah, contohnya guru yang mengajar tersebut masih ada yang tidak menggunakan media pembelajaran interaktif, sehingga ini mengakibatkan minat dan motivasi belajar Siswa Menengah Kejuruan terhadap pelajaran Sejarah menjadi berkurang. Permasalahan berikutnya, yang membuat motivasi belajar siswa Sekolah Menengah Kejuruan minim terhadap pelajaran Sejarah, adalah akibat dari pola tingkah laku dan lingkungan sekolah dari siswa SMK. Pada dasarnya,mayoritas karakter dan pola pikir dari para siswa SMK tersebut, berbeda dengan siswa SMA. Hal iniditinjau dari ambisi dan orientasi masa depan yang dimiliki oleh kedua siswa tersebut. Hal ini dikarenakan jika siswa SMA mayoritasnya berambisi dan berorientasi dalam pencapaian nilai - nilai akademik agar bisa melanjutkan perkuliahan di perguruan tinggi terbaik, sementara dari para siswa SMK itu sendiri, cenderung kepada pengembangan skill dan kemampuan yang siap pakai atau siap kerja.

Agar pembelajaran sejarah lebih kondusif di lingkungan belajar Siswa Sekolah Menengah Kejuruan tersebut, maka disinlah peran seorang guru sangat diperlukan dalam memberikan bimbingan dan arahan positif kepada siswa SMK tersebut agar menyukai pelajaran sejarah, khususnya sejarah lokal. (Reksoatmodjo, 2010, hlm : 5).

Orientasi efektif yang harus di ubah dari guru sejarah di Sekolah Menengah Kejuruan atau SMK adalah berusaha membangun kembali kreativitas skill terbaik dalam mengupayakan agar mampu menciptakan pemilihan model pembelajaran interaktif dan komunikatif dengan media game teaching Ludo, merupakan adaptasi dari salah satu permainan yang sanga digemari oleh siswa di SMK Labor Binaan FKIP UNRI, di Pekanbaru. Melalui pengembangan model pembelajaran game ludo interaktif tersebut, dapat memberikan sugesti kepada siswa menengah kejuruan, jika belajar sejarah bukanlah hal yang membosankan, namun sebaliknya justru merupakan mata pelajaran yang sangat menyenangkan untuk dipelajari.

Pentingnya pemilihan game teaching ludo yang dikembangkan sebagai media belajar di masa sekarang, dilatarbelakangi oleh adanya rekonstruksi di dalam sistematika kurikulum pendidikan nasional Indonesia yang mengacu kepada sistem pembelajaran bersifat cooperative learning, melalui cara guru dalam menciptakan model pembelajaran seru dan membangun, namun tidak lari dari pedoman dasar kurikulum pendidikan 2013.

Komposisi dari kurikulum 2013 yang harus dipahami oleh para guru di sekolah agar pembelajaran sejarah dapat berjalan kondusif di SMK, yaitu dengan cara menciptakan 


\section{SHEs: Conference Series 3 (2) (2020) 252- 266}

model pembelajaran yang berpedoman pada kurikulum berbasis kompetensi dan karakter secara terpadu berdasarkan penyempurnaan Kurikulum Tingkat Satuan Pendidikan tahun 2006. (Sudjimat,2014,hlm:3).

Berpedoman dengan gagasan yang diprakarsai oleh Reksoatmojo (2010), pada dasarnya perspektif dari siswa Sekolah Menengah Kejuruan (SMK) lebih mengedepankan kepada hal yang disebut orientasi, justifikasi, fokus, standar keberhasilan di sekolah, pekerjaan, hubungan antara sekolah dengan perindustrian, lingkungan masyarakat dengan kalangan para pemerintah, serta, responsiveness dengan logistik dan pembiayaan.

Permasalahan selanjutnya, yang menjadi dasar bagi para peneliti untuk merangkum perlunya pembaharuan baru pada metode pembelajaran sejarah secara interaktif dengan teknik metode game ludo teaching di sekolah adalah pendekatan yang inklusif antara guru sejarah dan siswa di sekolah tersebut belum terjalin utuh secara maksimal. Namun didukung dengan konsep cara guru mengajar yang tidak relevansi dengan kehendak atau keinginan siswa selama ini, sehinga terjadilah permasalahan yang sangat intensif, yaitu sekolah tersebut sering sekali mengalami pergantian guru sejarah.

Tujuan penelitian pengembangan model pembelajaran interaktif Ludo Teaching bagi siswa SMK di mata pelajaran Sejarah, adalah untuk mengetahui arti dari proses terjadinya pengembangan, media pembelajaran interaktif, makna dari pembelajaran interaktif sejarah perlu dilakukan, penjelasan model pembelajaran game teaching, cara pengaplikasian Ludo Teaching, arti motivasi belajar dalam pembelajaran, mengetahui cara meningkatkan berpikir kritis pada siswa SMK, dan mengetahui proses evaluasi hasil belajar siswa dengan game Ludo Teaching.

Ludo Teaching adalah contoh media pembelajaran yang dikembangkan oleh guru. Meninjau dari manfaat penting pada media itu sendiri, Gagne dan Briggs (2006) dalam Arsyad menjelaskan pengertian Media Pembelajaran, yaitu kegiatan proses pembelajaran yang meliputi alat yang secara fisik yang digunakan untuk menyampaikan isi materi pengajaran, yang terdiri dari antara lain buku, tape recorder, kaset, video camera, video recorder, film, slide (gambar bingkai), foto, gambar, grafik, televisi, dan komputer.

\section{METODE}

Penelitian ini dilakukan terhadap siswa Kelas Satu Semua Jurusan di Sekolah Menengah Kejuruan (SMK) Labor Binaan FKIP UNRI, Pekanbaru. Penelitian ini bertujuan untuk mengembangkan sebuah media pembelajaran interaktif, maka metode penelitian yang digunakan adalah metode Reseach and Development (R\&D), yaitu penelitian dan pengembangan. Sesuai dengan pendapat yang dikemukakan Borg \& Gall (1979 : 624), yaitu Educational reseach and development $(R \& D)$ is a process used ti develop and validae aduational product. Dari pengembangan metode Reseach and Development tersebut, maka peneliti dapat mengkolaborasikan dengan metode studi kasus. Yaitu, menetapkan metode tersebut sebagai acuan dasar dalam menetapakan desain produk game teaching Ludo yang akan dihasilkan sebagai model dari pengembangan media pembelajaran yang inovatif dan kreatif bagi siswa. Untuk mencapai hasil penelitian yang maksimal, peneliti juga menyertakan model Spiral Kemmis and Mc Taggart (2006), dalam Suharmis, meliputi tiga tahap, diantaranya adalah perencanaan, pengamatan dan refleksi. Penelitian ini menggunakan beberapa instrumen, yaitu soal tes untuk mengukur ketercapaian variabel, selain soal tes terdapat lembar observasi untuk mengukur ketercapaian variabel, dan instrumen terakhir adalah lembar lembar observasi keterlaksanaan modal cooperative learning dapat mudah terimpelementasikan pada media game teaching. 


\section{SHEs: Conference Series 3 (2) (2020) 252- 266}

\section{HASIL DAN PEMBAHASAN}

Johnson (2009: 183) menyatakan berpikir kritis merupakan proses terarah yang digunakan pada kegiatan mental unuk memecahkan masalah, mengambil keputusan, menganalisis pendapat pada penelitian ilmiah. Cottrell (2005) mengemukakan , bahwa "Critical thinking is a cognitive activity, associated with using the mind", artinya berpikir secara kritis adalah aktifitas yang bersifat kognitif, dan berhubungan dengan penggunan pikiran.

Menurut Bloom, kemampuan berpikir kritis untuk menempati dimensi analisis (C4), sintesis (C5), dan evaluasi (C6). Anderson \& Krathwohl (2010) menjelaskan bahwa dimensi analisis menyebabkan timbulnya pemecahan materi menjadi bagian-bagian kecil yang saling terhubung. Dimensi tersebut meliputi kognitif yang berguna untuk tahap mengorganisasi dan mendistribusikan. Anderson \& Krathwohl (2010) mendefinisikan dimensi evaluasi sebagai dimensi pengambilan keputusan berdasarkan kriteria dan standar tertentu. Kriteria-kriteria yang biasanya digunakan yaitu kualitas, efektivitas, efisien, dan konsistensi.

Nitko \& Brookhart (2011) berpendapat bahwa kemampuan berpikir kritis paling baik diukur dan dinilai dalam konteks pembelajaran tertentu. Guru mengukur kemampuan berpikir kritis perlu mengejawantahkan indikator - indikator kemampuan ke dalam konteks materi pembelajaran. Selain itu, sangatlah penting bagi peneliti untuk menghubungkan materi pembelajaran berupa pengukuran terhadap kemampuan berpikir kritis. Sesuai dengan pendapat Niko \& Brookhar, adalah :

Klarifikasi Dasar, Dukungan dasar, Menyimpulkan, Klarifikasi tingkat lanjut, dan strategi serta taktik. 
Tabel 1. Aspek Kemampuan Berpikir Kritis Siswa

\begin{tabular}{|c|c|c|}
\hline Kategori & Indikator & Contoh indikator soal \\
\hline & $\begin{array}{l}\text { 1. Fokus pada } \\
\text { pertanyaan }\end{array}$ & $\begin{array}{l}\text { Disajikan sebuah masalah/problem aturan, } \\
\text { kartun, atau eksperimen dan hasilnya, peserta } \\
\text { didik dapat menentukan masalah utama, } \\
\text { kriteria yang digunakan untuk mengevaluas } \\
\text { kualitas, kebenaran araumen atau kesimpulan }\end{array}$ \\
\hline
\end{tabular}

Melakukan

Klarifikasi

dasar

2. Menganalisis argumen
Disajikan deskripsi sebuah situasi atau satu/dua argumentasi, peserta didik dapat: (1) menyimpulkan argumentasi secara cepat, (2) memberikan alasan yang mendukung argumen yang disajikan, (3) memberikan alasan tidak mendukung argumen yang disajikan.

Disajikan sebuah teks argumentasi, iklan, atau eksperimen dan interpretasinya, peserta didik menentukan bagian yang dapat dipertimbangan untuk dapat dipercaya (atau tidak dapat dipercaya), serta memberikan alasannya.

kredibilitas sumber

4. Membuat Kesimpulan

Membuat secara deduktif
Disajikan sebuah pernyataan yang diasumsikan kepada peserta didik adalah benar dan pilihannya terdiri dari: (1) satu kesimpulan yang benar dan logis, (2) dua atau lebih kesimpulan yang benar dan logis, peserta didik dapat membandingkan kesimpulan yang sesuai dengan pernyataan yang disajikan atau kesimpulan yang harus diikuti. 


\section{SHEs: Conference Series 3 (2) (2020) 252- 266}

\begin{tabular}{ll}
\hline 5. Membuat & Disajikan sebuah pernyataan, informasi/data, \\
kesimpulan & dan beberapa kemungkinan kesimpulan, \\
secara induktif & peserta didik dapat menentukan sebuah \\
kesimpulan yang tepat dan memberikan \\
alasannya
\end{tabular}

6. menilai definisi Disajikan deskripsi sebuah situasi, pernyataan masalah, dan kemungkinan penyelesaian masalahnya, peserta didik dapat menentukan:

(1) solusi yang positif dan negatif, (2) solusi mana yang paling tepat untuk memecahkan masalah yang disajikan, dan dapat memberikan alasannya.

Melakukan

klarifikasi tingkat lanjut 7.mendefinisikan asumsi
Disajikan sebuah argumentasi, beberapa pilihan yang implisit di dalam asumsi, peserta didik dapat menentukan sebuah pilihan yang tepat sesuai dengan asumsi.

Higher Order Thinking Skill (Hots)

Menurut Brookhart (2011), Fungsi HOTS (Higher Order Thinking Skill) dalam praktek media game teaching Ludo pada tahap evaluasi siswa di mata pelajaran Sejarah, dibagi menjadi tiga, yaitu :

1. Kemampuan berpikir tingkat tinggi berada pada bagian atas taksonomi kognitif Bloom yang meliputi kemampuan analisis, evaluasi dan mencipta

2. Tujuan pembelajaran taksonomi kognitif adalah membekali peserta agar dapat melakukan proses transfer pengetahuan

3. Kemampuan berpikir aartinya peserta didik mampu menerapkan pengetahuan dan keterampilan

Schraw et al. (2011: 191) mengklasifikasikan arti keterampilan berpikir menjadi dua tingkatan yaitu keterampilan berpikir tingkat rendah (Lower Order Thinking Skills), terdiri atas pengetahuan dan pemahaman, serta keterampilan berpikir tingkat tinggi (Higher Order Thinking Skills) yang terdiri atas aplikasi, analisis, dan evaluasi.

Pada pengimplementasian butir-butir soal meliputi tentang media interaktif game teaching Ludo, harus memenuhi tiga standar operasional, mengacu kepada Taksonomi Bloom. Yaitu : 
Tabel 2. Tiga Standar Operasional, Mengacu Kepada Taksonomi Bloom

\begin{tabular}{|c|c|c|}
\hline \multicolumn{2}{|c|}{ Tingkat HOTS } & Kata Operasional \\
\hline Analisis: & $\begin{array}{l}\text { dapatkah peserta didik membedakan } \\
\text { antara konsep-konsep yang berbeda? }\end{array}$ & $\begin{array}{l}\text { Menilai, membandingkan, } \\
\text { mengkritik, mengurutkan, } \\
\text { membedakan, } \\
\text { menentukan, } \\
\text { mengurutkan }\end{array}$ \\
\hline Evaluasi: & $\begin{array}{l}\text { dapatkah peserta didik membenarkan } \\
\text { suatu pernyataan atau pilihan tertentu dengan } \\
\text { memberikan alasan }\end{array}$ & $\begin{array}{l}\text { Mengevaluasi, menilai, } \\
\text { mengkritik, } \\
\text { memilih/menyeleksi, } \\
\text { menghubungkan, } \\
\text { memberikan pendapat }\end{array}$ \\
\hline encipta: & $\begin{array}{l}\text { patkah peserta didik membuat atau } \\
\text { gkan produk, teori atau sudut pandang baru } \\
\text { pembelajaran? }\end{array}$ & $\begin{array}{l}\text { Merakit, mendisgn, } \\
\text { merancang, membuat, } \\
\text { memformulasikan. }\end{array}$ \\
\hline
\end{tabular}

Oleh karena itu, berdasarkan kesimpulan penjelasan tentang HOTS tersebut peneliti menetapkan sebuah kesimpulan hasil analisis penelitian tentang presentase kemampuan berpikir kritis siswa kelas satu di SMK Labor Binaan FKIP UNRI berdasarkan uji validitas jenis prototype media pembelajarn interaktif berbasis aplikasi android berupa game teaching Ludo.

Tabel 3. Kisi-kisi Instrumen observasi Siswa pada pelaksanaan pembelajaran dengan metode studi kasus

\begin{tabular}{lll}
\hline No & Aspek yang diamati & Indikator \\
\hline 1 & Tahap persiapan & Mengenali gejala \\
& Mendeskripsikan persoalan \\
& Menentukan masalah \\
& Menjabarkan masalah menjadi \\
& kensep pemikiran yang jelas. \\
& Membuat hipotesis dasar permasalahan \\
& bisa terjadi \\
& Membuat hipotesis akibat yang terjadi \\
& serta mengatasinya \\
\end{tabular}


SHEs: Conference Series 3 (2) (2020) 252- 266

$\begin{array}{ll} & \text { Memilih serta menentukan } \\ & \text { tahapan langkah-langkah yang } \\ & \text { tepat } \\ & \text { Mengumpulkan informsi } \\ & \text { Kesimpulan hasil observasi }\end{array}$

Jadi, metode studi kasus yang digunakan, dari semua jurusan tersebut, setelah peneliti melakukan observasi selama 2 minggu, diperoleh data sebagai berikut. Yaitu :

Tabel 4. Laporan Observasi Minggu Pertama

\begin{tabular}{|c|c|c|c|c|c|c|}
\hline \multirow[t]{5}{*}{ No } & \multirow[t]{5}{*}{ Nama Jurusan } & \multicolumn{2}{|c|}{ Jumlah Siswa } & \multirow{4}{*}{\multicolumn{2}{|c|}{$\begin{array}{l}\text { Persentase } \\
\text { Motivasi } \\
\text { Belajar } \\
\text { Siswa }\end{array}$}} & \multirow{5}{*}{$\begin{array}{l}\text { Hasil } \\
\text { Keseluruhan } \\
\text { Persentase } \\
\text { Motivasi Belajar }\end{array}$} \\
\hline & & \multirow[b]{4}{*}{ Pria } & \multirow[b]{4}{*}{ Wanita } & & & \\
\hline & & & & & & \\
\hline & & & & & & \\
\hline & & & & Pria & Wanita & \\
\hline 1 & Administarsi Perkantoran & 13 & 37 & $65 \%$ & $75 \%$ & $70 \%$ \\
\hline 2 & Akuntansi & 20 & 40 & $50 \%$ & $62 \%$ & $56 \%$ \\
\hline 3 & Manajemen Pemasaran & 14 & 2 & $73 \%$ & $70 \%$ & $72 \%$ \\
\hline 4 & $\begin{array}{l}\text { Teknik Komputer dan } \\
\text { Jaringan }\end{array}$ & 17 & 3 & $45 \%$ & $50 \%$ & $48 \%$ \\
\hline 5 & Rekayasa Perangkat Lunak & 20 & 5 & $50 \%$ & $55 \%$ & $53 \%$ \\
\hline
\end{tabular}




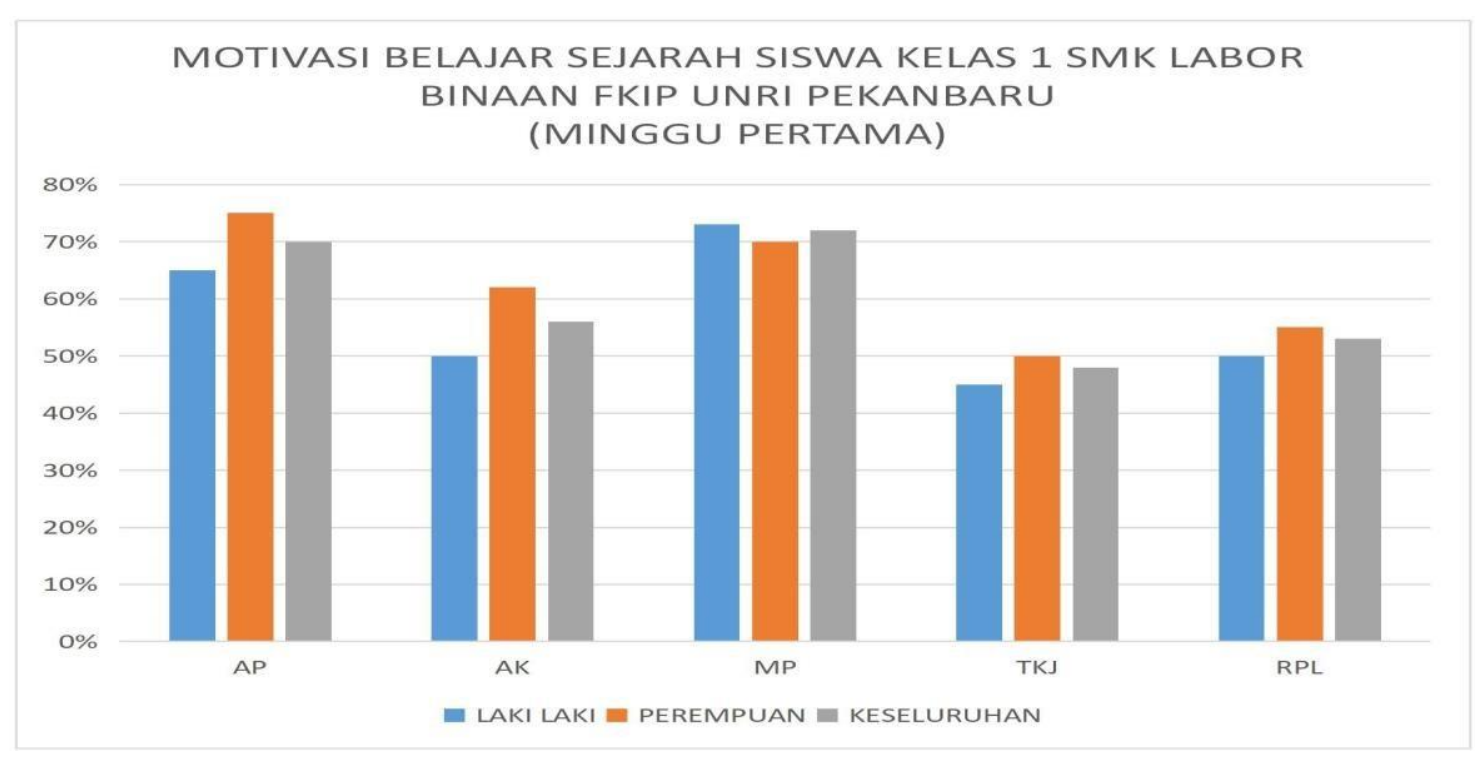

Gambar 1. Grafik Observasi Minggu Pertama

MOTIVASI BELAJAR SEJARAH SISWA KELAS 1 SMK LABOR BINAAN FKIP UNRI PEKANBARU

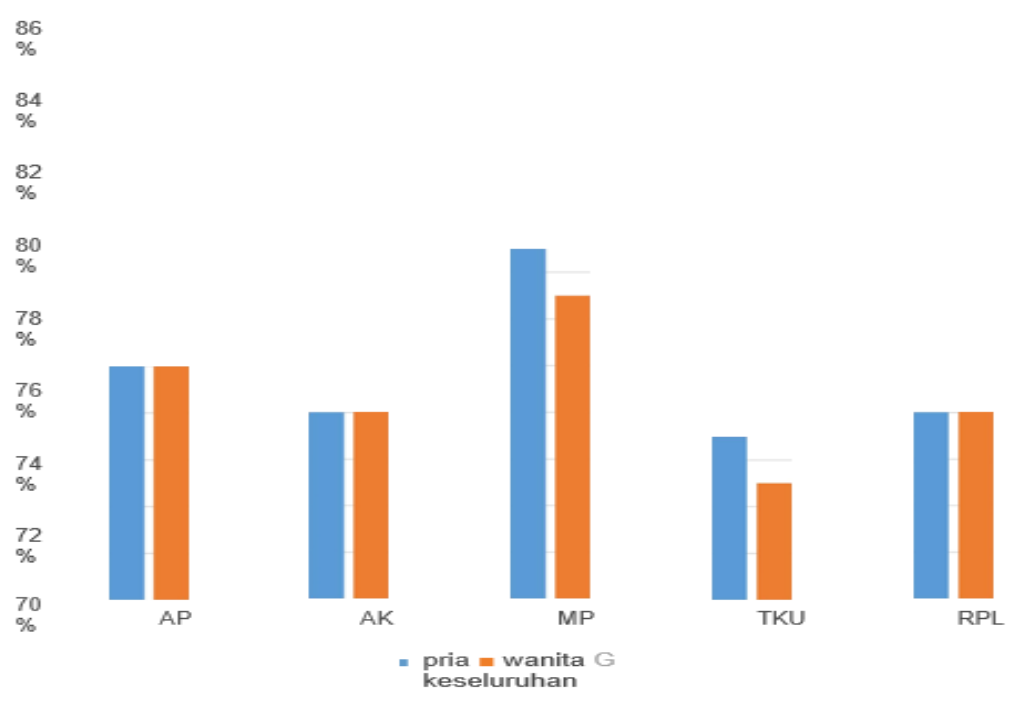

Gambar 2. Grafik Observasi Minggu Kedua 
SHEs: Conference Series 3 (2) (2020) 252- 266

Tabel 5. Laporan Observasi Minggu Kedua

\begin{tabular}{|c|c|c|c|c|c|c|}
\hline \multirow[t]{2}{*}{ No } & \multirow[t]{2}{*}{ Nama Jurusan } & \multicolumn{2}{|c|}{ Jumlah Siswa } & \multicolumn{2}{|c|}{$\begin{array}{l}\text { Persentase } \\
\text { Motivasi } \\
\text { Belajar Siswa }\end{array}$} & \multirow[t]{2}{*}{$\begin{array}{l}\text { Hasil Keseluruhan } \\
\text { Persentase } \\
\text { Motivasi Belajar }\end{array}$} \\
\hline & & Pria & Wanita & Pria & Wanita & \\
\hline 1 & Administarsi Perkantoran & 13 & 37 & $80 \%$ & $80 \%$ & $80 \%$ \\
\hline 2 & Akuntansi & 20 & 40 & $78 \%$ & $80 \%$ & $79 \%$ \\
\hline 3 & Manajemen Pemasaran & 14 & 2 & $85 \%$ & $83 \%$ & $84 \%$ \\
\hline 4 & Teknik Komputer dan Jaringan & 17 & 3 & $77 \%$ & $75 \%$ & $76 \%$ \\
\hline 5 & Rekayasa Perangkat Lunak & 20 & 5 & $78 \%$ & $80 \%$ & $79 \%$ \\
\hline
\end{tabular}


SHEs: Conference Series 3 (2) (2020) 252- 266

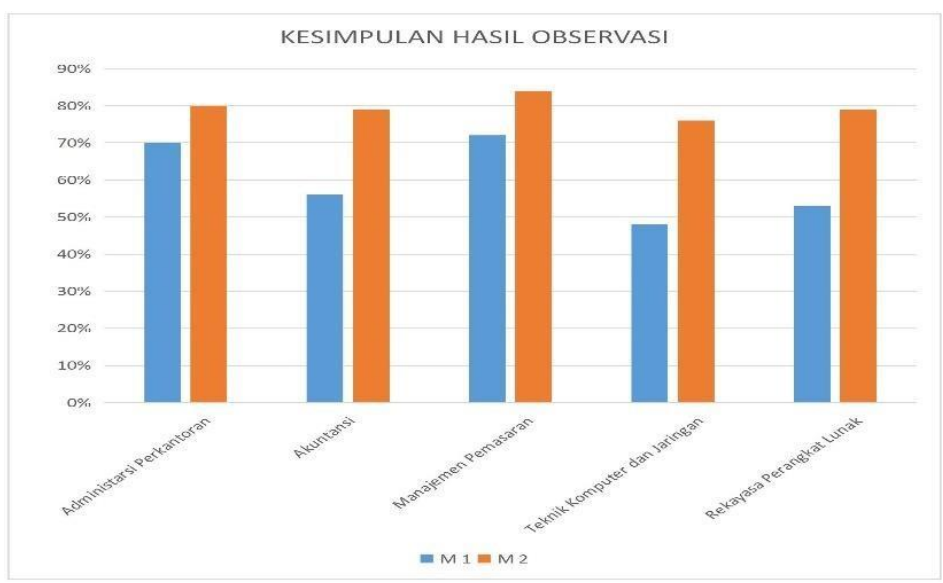

Gambar 3. Kesimpulan Hasil Observasi

Tabel 6. Hasil Analisis Keseluruhan Prestasi Belajar Siswa Smk Labor Binaan Fkip Unri Pekanbaru

\begin{tabular}{|c|c|c|c|c|c|c|c|c|c|c|c|}
\hline \multirow[t]{3}{*}{ No } & \multirow[t]{3}{*}{ Jurusan } & \multicolumn{2}{|c|}{$\begin{array}{l}\text { Jumlah } \\
\text { Siswa }\end{array}$} & \multicolumn{4}{|c|}{ Minggu Pertama } & \multicolumn{4}{|c|}{ Minggu Kedua } \\
\hline & & \multirow[t]{2}{*}{ L } & \multirow[t]{2}{*}{$P$} & \multirow{2}{*}{$\begin{array}{c}\mathrm{L} \\
\text { Tuntas }\end{array}$} & \multirow{2}{*}{$\begin{array}{c}\text { L } \\
\text { Tidak } \\
\text { tuntas }\end{array}$} & \multirow{2}{*}{$\begin{array}{c}\mathrm{P} \\
\text { Tuntas }\end{array}$} & \multirow{2}{*}{$\begin{array}{c}\text { P } \\
\text { Tidak } \\
\text { Tuntas }\end{array}$} & \multirow{2}{*}{$\begin{array}{c}\mathrm{L} \\
\text { Tuntas }\end{array}$} & \multirow{2}{*}{$\begin{array}{c}\text { L } \\
\text { Tidak } \\
\text { tuntas }\end{array}$} & \multirow{2}{*}{$\begin{array}{c}P \\
\text { Tuntas }\end{array}$} & \multirow{2}{*}{$\begin{array}{c}\text { P } \\
\text { Tidak } \\
\text { Tuntas }\end{array}$} \\
\hline & & & & & & & & & & & \\
\hline \multicolumn{12}{|l|}{1} \\
\hline & $\begin{array}{l}\text { Administrasi } \\
\text { Perkantoran }\end{array}$ & 13 & 37 & 6 & 7 & 20 & 17 & 10 & 3 & 30 & 7 \\
\hline & Manajeme $n$ & & & & & & & & & & \\
\hline \multirow[t]{2}{*}{3} & Pemasaran & 14 & 2 & 8 & 6 & 2 & 0 & 12 & 2 & 2 & 0 \\
\hline & $\begin{array}{l}\text { Teknik } \\
\text { Komputer }\end{array}$ & & & & & & & & & & \\
\hline \multirow[t]{2}{*}{4} & $\begin{array}{l}\text { dan } \\
\text { Jaringan }\end{array}$ & 17 & 3 & 10 & 7 & 1 & 2 & 14 & 3 & 3 & 0 \\
\hline & $\begin{array}{l}\text { Rekayasa } \\
\text { Perangkat }\end{array}$ & & & & & & & & & & \\
\hline \multirow[t]{2}{*}{5} & Lunak & 20 & $j$ & 12 & 8 & 3 & 2 & 17 & 3 & 4 & 1 \\
\hline & JUMLAH & & & 46 & 38 & 48 & 39 & 68 & 16 & 74 & 13 \\
\hline
\end{tabular}




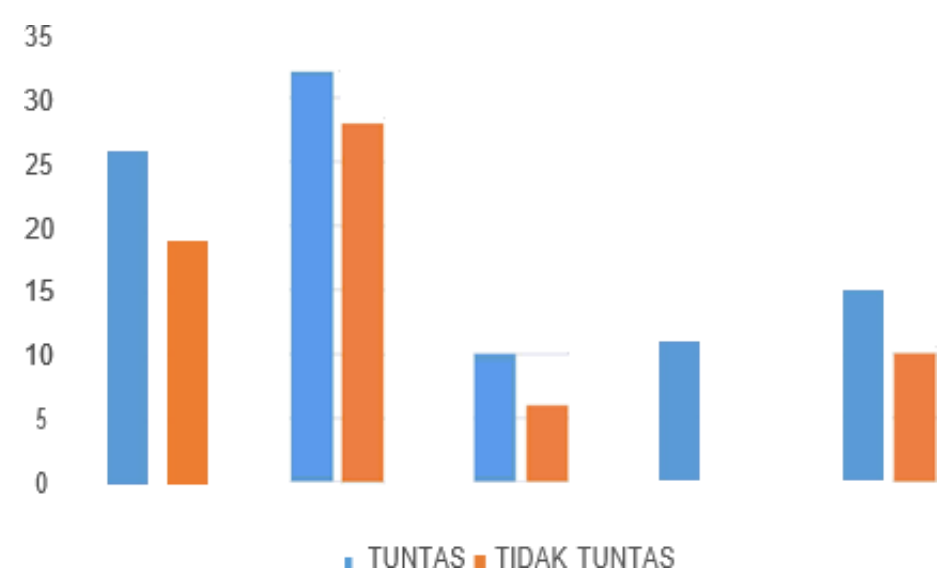

\section{Gambar 4. Laporan Hasil Tes Nilai Pelajaran Sejarah Siswa Smk}

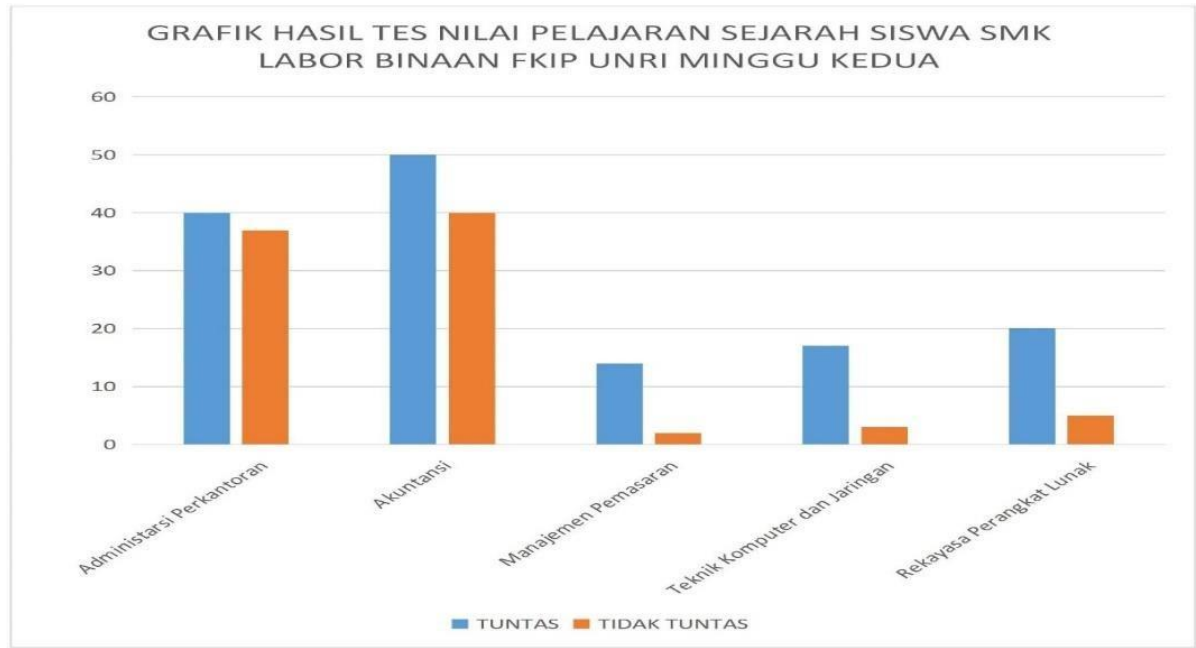

\section{Labor Binaan Fkip Unri Minggu Pertama Dan Minggu Kedua}

Gambar 5. Laporan Hasil Tes Nilai Pelajaran Sejarah Siswa Smk Labor Binaan Fkip Unri Minggu Pertama Dan Minggu Kedua

\section{SIMPULAN}

Dengan demikian berdasarkan hasil data anasis data yang disajika diatas dapat ditarikkesimpulan jika, hasil observasi dan tes yang dilakukan oleh peneliti dalam jangka waktu dua minggu mengalami peningkatan yang baik dan jelas dari pertemuan pada minggu sebelumnya .

\section{DAFTAR PUSTAKA}

Aditya Bakti Soeparno (1988). Media Pengajaran Bahasa. Jakarta: PT Inter-Pariwisata.

Arief S. Sadiman, dkk (2006) Media Pendidikan: Pengertian, Pengembangan, dan

Pemanfaatannya. Edisi Pertama. Jakarta: PT Raja Grafindo Persada

Arikunto Suharsimi, 2013. Prosedur Penelitian. Jakarta : Rineka Cipta 
Creswell, J.W. (2008). Educational Research, Planning, Conducting, and Evaluating Quantitative and Qualitative Research. Third Edition. New Jersey: Pearson Education Merrill Prentice Hall.

Cresweel, Jhon W. 2012. Educational Reseach Planning, Conducting, and Evluating, Quantitative and Qualitative Reseah Fourth Edition. United States of America: PEARSON

Depdiknas (2003) Media Pembelajaran. Jakarta : Depdiknas

Djamarah, Syaiful Bahri dan Aswan Zain, 2002, Strategi Belajar Mengajar, Cetakan Kedua, Jakarta: Rineka Cipta

Hamdani, dkk. 2011, Strategi Belajar Mengajar. Pustaka Setia, Bandung.

Heinich, Robert, Michael Molenda, James D. Russel, (1982) Instructional Media: and the New Technology of Instruction, New York: Jonh Wily and Sons.

Husein Umar, 1999, Riset Sumber Daya Manusia Dalam Organisasi, PT Gramedia Pustaka Utama, Jakarta

Efetif. PT Bumi Aksara. Jakarta.

Latief, M.A. (2009). Penelitian Pengembangan. Malang: Fakultas Sastra, Universitas Negeri Malang

Mantra, I.B. (2004). Filsafat Penelitian \& Metode Penelitian Sosial. Yogyakarta: Pustaka Pelajar.

MC. Millan, J.H. \& Schumacher, S. (2001). Research in Education, A Conceptual Introduction. Fifth Edition. New York: Addison Wesley Longman, Inc.

Pribadi A, Benny. 2009, Model Desain Sistem Pembelajaran. PT Dian Rakyat. Jakarta. Sugiyono. 2012. Metode Penelitian Kuantitatif kualitatif dan R\&D. Bandung : Penerbit Alfabeta.

Trigueros, Roxana. 2017. Qualitative and Quantitative Reseach Instrument Reseach Books. Elsalvador : University Elsalvador Press

Uno B, Hamzah. 2007, Model Pembelajaran: Menciptakan Proses Belajar Mengajar yang Kreatif 